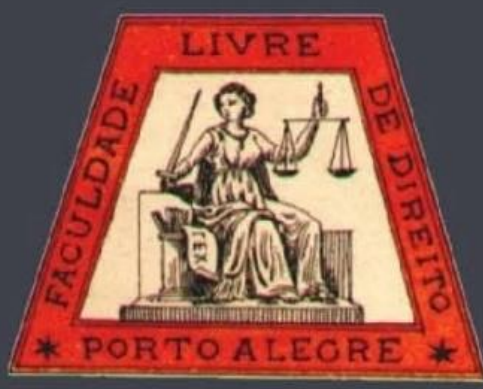

\title{
Assessoria Jurídica Hernani Estrella: ambiente de desenvolvimento do empreendedorismo e fomento do aprendizado do Direito Empresarial
}

Legal Aid Hernani Estrella: environment for development of entrepreneurship and promotion of Business Law learning

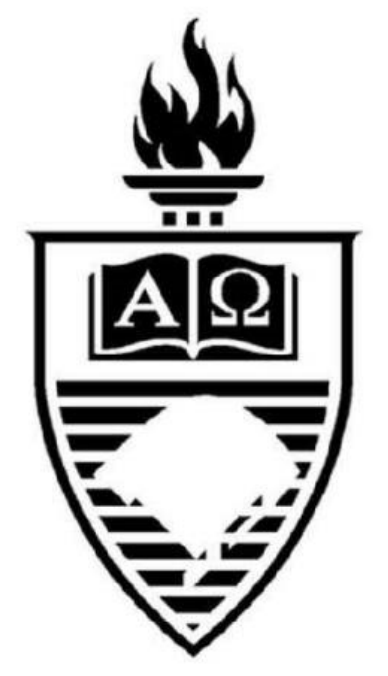

\section{Fernando Baguinski}

Universidade Federal do Rio Grande do Sul

\section{Gerson Luiz Carlos Branco}

Universidade Federal do Rio Grande do Sul

\section{Monalisa Renata Artifon}

Universidade Federal do Rio Grande do Sul

\section{UFRGS}




\title{
Assessoria Jurídica Hernani Estrella: ambiente de desenvolvimento do empreendedorismo e fomento do aprendizado do Direito Empresarial
}

\author{
Legal Aid Hernani Estrella: environment for development of entrepreneurship and promotion of \\ Business Law learning
}

Fernando Baguinski *

Gerson Luiz Carlos Branco**

Monalisa Renata Artifon ${ }^{* * *}$

\section{REFERÊNCIA}

BAGUINSKI, Fernando; BRANCO, Gerson; ARTIFON, Monalisa. Assessoria Jurídica Hernani Estrella: ambiente de desenvolvimento do empreendedorismo e fomento do aprendizado do Direito Empresarial. Revista da Faculdade de Direito da UFRGS, Porto Alegre, n. 36, vol. esp., p. 30-39, out. 2017.

\section{RESUMO}

A Assessoria Jurídica Hernani Estrella consiste em uma atividade de extensão composta por alunos de diferentes semestres da Faculdade de Direito da UFRGS. A Assessoria surgiu com o objetivo de facilitar o acesso dos pequenos empresários às informações que lhes são essenciais ao desempenho da atividade empresarial, por destinar-se ao atendimento daqueles indivíduos sem condição econômica suficiente para arcar com as custas de um advogado. A AJHE presta assessoria à uma gama variada de empreendedores, sendo os principais assistidos as empresas juniores, havendo, além destas, microempresários, startups e empresários individuais. Ao mesmo tempo em que a AJHE propicia aos estudantes da Universidade o aprimoramento dos conhecimentos no âmbito do direito empresarial, possibilita, ainda, que estes mantenham contato com a prática diária, preparando-os para o mercado externo. Cinco são os grupos que compõem a Assessoria Jurídica Hernani Estrella, quais sejam, Direito Societário, Direito Tributário, Propriedade Intelectual e Direito Contratual, os quais são coordenados pelos próprios alunos, que recebem auxílio, principalmente, de ex-graduandos da Universidade e de ex-membros da Assessoria.

\section{PALAVRAS-CHAVE}

Assessoria Jurídica Hernani Estrella. Direito Empresarial. Empresas Juniores. Empreendedorismo.

\section{ABSTRACT}

The Legal Advice Hernani Estrella is an extension activity composed by students of different levels from the Law School of the Federal University of Rio Grande do Sul. It has begun with the propose of helping small businessmen to access essential business activity information and was focused on individuals without economic conditions to pay for a lawyer. The AJHE provides advice to different businessmen, mainly junior companies, but it also helps microentrepreneurs, startups and individual businessmen. At the same time AJHE improves the knowledge of the students about the context of Business Law, through the contact with the daily experience, preparing them for the professional field. There are five work groups: Corporate Law, Tax Law, Intellectual Property and Contractual Law, which are coordinated by the students themselves and receive assistance from former students of the University and ex-members of the AJHE.

\section{KEYWORDS}

Legal Advising Hernani Estrella. Corporate Law. Junior companies. Entrepreneurship.

\section{SUMÁRIO}

\footnotetext{
${ }^{*}$ Estudante de graduação do curso de Ciências Jurídicas e Sociais da Universidade Federal do Rio Grande do Sul.

${ }_{* * *}^{*}$ Professor Adjunto de Direito Empresarial da Universidade Federal do Rio Grande do Sul. Doutor em Direito pela UFRGS. Professor coordenador da atividade de extensão Assessoria Jurídica Hernani Estrella.

**** Estudante de graduação do curso de Ciências Jurídicas e Sociais da Universidade Federal do Rio Grande do Sul.
} 
Introdução. 1. Empresa, mercado e o papel da AJHE. 2. Surgimento da AJHE, trajetória e impacto na UFRGS. Conclusão. Referências.

\section{INTRODUÇÃO}

Este artigo é um relatório de extensão que descreve $\mathrm{o}$ resultado das atividades desenvolvidas pelo programa de extensão Assessoria Jurídica Hernani Estrella ("AJHE"). O programa de extensão AJHE foi estruturado aos moldes de um ambiente acadêmico que propicia o desenvolvimento da prática empresarial, ao mesmo tempo em que fomenta o estudo teórico e compreensão prática do Direito Empresarial e dos problemas da vida da empresa. ${ }^{1}$

A atividade de extensão realizada pela AJHE consiste na disponibilização das atividades de consultoria e assessoria jurídica de natureza extrajudicial pelos alunos do Curso de Direito da UFRGS para a comunidade empresarial que não pode contratar serviços especializados no mercado jurídico.

A relevância pedagógica da Assessoria Jurídica Hernani Estrella decorre do fato de que não há como efetivar um aprendizado pleno do Direito Empresarial desligado da prática jurídica. Isso ocorre porque esse ramo do Direito, mais do que puramente teórico, é intensamente prático. $\mathrm{O}$ Direito Empresarial diuturnamente renova-se através das práticas e tendências do mercado, conforme as necessidades econômicas e a mecânica social que lhes envolve, as quais se processam de modo cada vez mais célere e impactante. Conforme mencionava Tullio Ascarelli, o Direito Comercial é uma verdadeira "categoria histórica", com um caráter "fragmentário" derivado de sua contínua necessidade de adaptação às transformações da vida econômica e social. ${ }^{2}$

Ascarelli compreendia a importância da extensão universitária e nesse sentido escreveu excerto extremamente importante para este artigo: "Se, como se lê no talvez mais célebre de todos os cursos jurídicos de extensão universitária, naquela obra prima constituída pelo Common law de Holmes - The life of the law has been experience, disso se pode encontrar confirmação no desenvolvimento histórico dos institutos do Direito Comercial". 3

A extensão jurídica resulta não só em interação entre a prática e a teoria, como também revela um caráter interdisciplinar da atividade, pois os estudantes precisam compreender a realidade econômica, contábil e administrativa das empresas para poder auxiliar os empresários, o que propicia a construção de um conhecimento aderente à realidade e integral dos fenômenos jurídico-sociais associados ao exercício da atividade empresarial, matéria que é objeto deste artigo.

\section{EMPRESA, MERCADO E O PAPEL DA AJHE}

Segundo a disposição do art. 170 da Constituição Federal, nossa ordem econômica é baseada na livre iniciativa e na valorização social do trabalho, o que torna o empreendedorismo um valor a ser preservado e fomentado, tendo em vista que cabe à empresa o papel de promotor das atividades econômicas e, portanto, realizar uma função relevante sob o ponto de vista social, tal como a dicção da disposição constitucional.

\footnotetext{
${ }^{1}$ Não obstante a AJHE desenvolva atividade de assistência social em razão de atuar em favor de pessoas que não possuem condições de contratar Advogados, a atividade de extensão enquadra-se como uma atividade não assistencialista, voltada fundamentalmente à formação acadêmica, pois compreende a extensão universitária "como processo definido e efetivado em função das exigências da realidade, indispensável na formação do aluno na qualificação do professor e no intercâmbio com a sociedade, o que implica em relações multi, inter ou transdisciplinar e inter-profissional”. JEZINE, Edineide. As Práticas Curriculares e a Extensão Universitária. Belo Horizonte. Anais do $2^{\circ}$ Congresso Brasileiro de Extensão Universitária Belo Horizonte - 12 a 15 de setembro de 2004.

2 ASCARELLI, Tullio. Panorama do Direito Comercial. Sorocaba: Minelli, 2007, p. 1-31.

${ }^{3}$ ASCARELLI, Tullio. Panorama do Direito Comercial. Sorocaba: Minelli, 2007, p. 25.
} 
A atuação da Assessoria Jurídica Hernani Estrella insere-se nesse propósito de valorização e fortalecimento da atividade empresarial, atividade que leva em conta a compreensão da relevância da empresa e seu papel econômico e os reflexos sociais de sua atuação. Compreendendo tais pontos, poderá se obter uma noção da relevância da atuação da AJHE para a formação dos estudantes, tendo em vista que apesar da crise que afeta o país nos últimos anos, no período precedente houve uma década de expansão da atividade empresarial e, consequentemente, foi ampliada a área de atuação dos profissionais do Direito no âmbito do Direito Empresarial.

A "empresa" é um tema de difícil enfrentamento sob o ponto de vista jurídico, não só por suas conexões com a economia e outras áreas do conhecimento, assim como pela dificuldade conceitual sob o ponto de vista jurídico-normativo. Embora seja predominante na doutrina a ideia de que é a noção econômica de empresa que alimenta a sua concepção jurídica, o tema é objeto de grande controvérsia, considerando que sob o ponto de vista legislativo o Código Civil não definiu diretamente a "empresa", embora tenha disciplinado o estatuto jurídico do "empresário".

O tema foi, inclusive, objeto de recente tese de doutorado de nossa universidade, na qual se defende as características e requisitos que permitem aos juristas aplicar o estatuto jurídico do empresário, como se vê do livro que resultou da tese, editado por Cássio Cavalli: "organização dos fatores de produção, trabalho do empresário, obtenção de produto destinado à troca em mercado voltado à satisfação de necessidades

\footnotetext{
${ }^{4}$ CAVALLI, Cássio. Empresa, Direito e Economia. Rio de Janeiro: Forense, 2013, p. 73-91.

${ }^{5}$ ASQUINI, Alberto. Perfis da empresa. Tradução de Fábio Konder Comparato. Revista de direito Mercantil, Industrial, Econômico e Financeiro. São Paulo, v. 35, n. 104, out./dez. de 1996.

${ }^{6}$ A esse propósito é importante a leitura de obra do jurista responsável pela elaboração do texto do Código Civil no capítulo relativo a empresa: MARCONDES, Sylvio. Problemas de Direito Mercantil, São Paulo: Saraiva, 1970. Do mesmo modo os textos a seguir tratam dessa problemática: MOREIRA ALVES, José Carlos. Inovações no novo Anteprojeto de Código Civil. Revista de Informação Legislativa, out/dez de 1973, p.5 - 15. REALE,
}

alheias, risco do próprio empresário que colhe os resultados de sua atividade voltado para o lucro"4.

Do mesmo modo, parte da doutrina afirma que foi a influência do Código Civil Italiano e do jurista Alberto Asquini que incentivaram o legislador brasileiro a adotar a concepção de que a empresa tem diferentes perfis jurídicos conforme os elementos que a integram, sendo, portanto, um fenômeno poliédrico ${ }^{5}$. O substrato econômico precisa ser traduzido em termos jurídicos para o referido autor, e tal tradução importará em diferentes perfis: o perfil funcional (empresa como atividade), subjetivo (sujeito exerce a atividade empresarial, o empresário), patrimonial ou objetivo (empresa como conjunto de bens e estabelecimento empresarial como universalidade de bens). Teria o legislador brasileiro unicamente rejeitado o perfil corporativo, resquício das ideias fascistas que inspiraram o Código Civil Italiano de 1942, onde também não vigora mais tal perfil, dadas as reformas realizadas após a segunda guerra mundial ${ }^{6}$.

Radicada na realidade econômica e social e imersa em um outro fenômeno importante para o Direito, que é o mercado, a empresa, especialmente as pequenas empresas brasileiras têm como permanente desafio a sua sobrevivência, visto além dos riscos econômicos inerentes à sua atividade, também há riscos jurídicos substanciais ${ }^{7}$.

Esta sobrevivência é desafiada pelo fato de que o empreendedor não dispõe da totalidade de informações de que precisa para dar sequência à sua atividade, especialmente $o$ pequeno empreendedor que não dispõe de um

Miguel. O Anteprojeto do Código Civil. São Paulo: Saraiva, 1972. REALE, Miguel. Visão geral do Projeto de Código Civil. Revista dos Tribunais, v. 752, jun. 1998 e MARTINSCOSTA, Judith e BRANCO, Gerson Luiz Carlos e Diretrizes Teóricas do novo Código Civil. São Paulo: Saraiva, 2002.

7 FORGIONI, Paula Andréa. A evolução no Direito Comercial Brasileiro: da mercancia ao mercado. São Paulo: Revista dos Tribunais, 2009 e ANTUNES, José Engrácia. Estrutura e responsabilidade da empresa: o moderno paradoxo regulatório. In: CUNHA, Alexandre dos Santos (Org.). O Direito da Empresa e das Obrigações e o novo Código Civil brasileiro. SP: Quartier Latin, 2006, p. 17-65. 
departamento jurídico ou mesmo experiência com a linguagem e com as peculiaridades da técnica jurídica.

Apesar disso, é essencial no mundo contemporâneo que o exercício da atividade empresarial o conhecimento de muitos institutos jurídicos, tendo em vista que o estatuto jurídico do empresário compreende o domínio, de modo profissional, do exercício de sua atividade e, portanto, das regras que disciplinam o exercício dessa atividade, o que torna obrigatório o conhecimento de matérias atinentes ao regime do direito da propriedade industrial, contratos empresariais e de consumo, o complexo sistema tributário brasileiro, o regime do Direito Societário, entre outras áreas ${ }^{8}$.

Para isso, o empreendedor precisa do auxílio de profissionais especializados para o exercício de sua atividade, ou em palavras do jargão do mercado, para "tocar seu negócio".

A AJHE atua para auxiliar o desenvolvimento da atividade empresária, sendo solicitado o auxílio pelos pequenos empreendedores, normalmente vinculados ao regime da micro e pequena empresa ${ }^{9}$.

Sob o ponto de vista fático, o consumidor e o pequeno empresário possuem similitude: limitação técnica (jurídica) e assimetria informativa perante o mercado. Porém, para evitar que o consumidor seja vítima de condutas oportunistas em razão da assimetria informacional, o Código de Proteção e Defesa do Consumidor estabelece um regime jurídico extremamente benéfico aos consumidores.

Porém, o regime jurídico dos empresários, ainda que pequenos ou iniciantes, não lhes permite alegar carência de informações ou desconhecimento de seus direitos ${ }^{10}$. Pelo contrário, na relação com os consumidores é considerado como fornecedor e terá que seguir um rigoroso regime de responsabilidade.

O empreendedor é considerado como um "profissional", alguém que presumivelmente possui conhecimento e técnica jurídica para o

\footnotetext{
8 WIEDMANN, Herbert. Direito Societário I Fundamentos. In: NOVAES E FRANÇA, Erasmo Valadão: Temas de Direito Societário, Falimentar e Teoria da Empresa. São Paulo: Malheiros, 2009.

${ }^{9}$ BRASIL. Lei Complementar $n^{\circ} 123$, de 14 de dezembro de 2006. Institui o Estatuto Nacional da Microempresa e da
}

desenvolvimento de suas atividades profissionais. A esse propósito é importante o clássico trabalho de Ronald Coase ao afirmar que a "empresa" é um feixe de contratos e que a prática de coordenação central e criação de homogeneidade é o elemento central da atividade empresarial, atuando não somente nas atividades internas com seus empregados e na "organização", como também na planificação dos contratos para distribuição de mercadorias e para insumos ${ }^{11}$.

Em outras palavras, não há como desenvolver a atividade empresarial de modo minimamente eficiente sem assessoria jurídica. Por essa razão e dada as dificuldades dos pequenos empresários brasileiros e também das empresas juniores da UFRGS, os quais não dispõem de recursos para obter tais informações e serviços jurídicos, a AJHE atua de modo a reduzir um de seus principais custos transacionais.

A importância da atuação da Assessoria Jurídica Hernani Estrella é, portanto, inquestionável, pois abrange vários aspectos da atividade empresarial - Propriedade Intelectual, Direito Societário, Direito Tributário e Contratual -, auxiliando o empreendedor a superar as barreiras informacionais que podem constituir obstáculo ao desenvolvimento da atividade dos pequenos empresários e das empresas juniores da UFRGS, principais usuários do sistema de assessoria da atividade de extensão.

Por outro lado, os empreendedores provêm aos estudantes um conjunto de complexas informações vinculadas à realidade econômica e social, o que proporciona uma rica relação de troca com os empreendedores, já que os acadêmicos do direito, auxiliados por egressos da Faculdade de Direito (pioneiros na AJHE) e por professores apreendem e auxiliam os empresários a compreender e conviver com o complexo normativo da burocracia estatal, em geral de difícil compreensão para os empresários iniciantes e para os estudantes cujos estudos ficam restritos às atividades em sala de aula.

Neste sentido a AJHE é um verdadeiro

Empresa de Pequeno Porte. Diário Oficial, Brasília, DF, 15 dez. 2006.

${ }^{10}$ CAVALLI, Cássio. Empresa, Direito e Economia. Rio de Janeiro: Forense, 2013, p. 169-186.

${ }^{11}$ COASE, R. H. The nature of the Firm. Economica, New Series, v. 4, n. 16, 1937, p. 386-405. 
laboratório que permite a congruência dos principais pilares da Universidade, que são a integração das atividades de ensino, pesquisa e extensão, proporcionando o convívio dos estudantes com atividades interdisciplinares, já que para auxiliar os empresários precisam de conhecimentos sobre $\mathrm{o}$ funcionamento das atividades econômicas, da organização das instituições, da contabilidade empresarial, etc.

A descrição das dificuldades realizada pelos empreendedores aos estudantes constitui um espaço peculiar de construção do conhecimento. Tem-se como comunicador um empresário com limitação econômica, técnica e muitas vezes cultural. $\mathrm{O}$ receptor da informação são estudantes, que na sua maioria são jovens entre 17 e 23 anos de idade, sem grandes experiências na vida econômica e apenas iniciantes no contato com a técnica jurídica.

Esse processo comunicativo é desafiador e rico, pois neste momento da vida profissional, os estudantes, com grande autonomia precisam enfrentar as diferenças culturais, sociais e técnicas para encontrar um modo de comunicar-se com eficiência, o que passa pela pesquisa acadêmica e pela reflexão sobre como são estruturadas as relações entre os agentes econômicos, os profissionais do direito e as instituições responsáveis pela aplicação ou controle da aplicação das normas jurídicas, tais como Poder Judiciário, Juntas Comerciais, INPI, etc.

Esse desafio contribui fortemente para a consolidação de um determinado perfil de profissional, mais preparado para os problemas da realidade, pois precisam saber comunicar o modo de solução e prevenção de conflitos, traduzindo a linguagem técnica de modo que seja acessível aos seus assistidos, que ora são pequenos empreendedores, ora são colegas de outros cursos encarregados das empresas juniores da Universidade.

Não se pode ignorar, também, que ainda de modo limitado, a Assessoria Jurídica Hernani Estrella torna o mercado mais acessível a segmentos periféricos da população, com isso valorizando a concorrência, a produtividade $\mathrm{e}$ também a função social da empresa $\mathrm{A}$ atividade empreendedora produz benefícios que não se limitam apenas ao empresário, mas irradiam-se na sociedade: ela gera riquezas, empregos e receita tributária, colabora para o avanço tecnológico, econômico e social do país, que adotou a livre iniciativa e, portanto, a empresa como modo de realizar o desenvolvimento econômico da nação. Nisto consiste sua função social: a empresa, indissociável da comunidade na qual se insere, com seu atuar promove benefícios para toda a sociedade, colaborando para seu desenvolvimento material. ${ }^{12}$. Tal função é valorizada e fortalecida pela atuação da AJHE, à medida que auxilia as empresas hipossuficientes a sobreviver no mercado e gerar os benefícios sociais característicos de sua atuação.

\section{SURGIMENTO DA AJHE, TRAJETÓRIA E IMPACTO NA UFRGS}

Assessoria Jurídica Hernani Estrella foi criada no ano de 2011 como um projeto de assessoria jurídica gratuita voltada para o ramo do Direito Empresarial, tendo em vista que o modelo de assessoria jurídica existente, nos moldes de um "escritório modelo", tal como é o SAJU, era voltado para áreas como o Direito de Família, Direito do Consumidor e Direito Civil, sendo extremamente limitada a possibilidade de acesso aos serviços, pela sua estrutura e princípios, ao Direito Empresarial e aos empresários.

Para os estudantes com interesse no Direito Empresarial era extremamente difícil a atuação na área, tendo em vista que os empresários dificilmente procuram serviços jurídicos não especializados, dadas as características da matéria e peculiaridades da área. Diante dessa realidade, um grupo de alunos decidiu organizar a AJHE e iniciou organizando por cinco grupos de atuação: Direito Tributário, Direito do Trabalho, Direito Societário, Propriedade Intelectual e Direito Contratual. Dadas as dificuldades relacionadas a ausência do propósito de atuação no contencioso judicial, a composição dos grupos foi alterada, tendo sido extinto o grupo de Direito do Trabalhista, permanecendo os demais.

\footnotetext{
${ }^{12}$ FRAZÃO, Ana. Função Social da Empresa. São Paulo: Renovar, 2011.
} 
Atualmente a AJHE é composta por 32 graduandos, os quais cursam diferentes semestres na Faculdade de Direito da UFRGS. Além disso, atuam na atividade de extensão advogados, quase todos ex-graduandos da Faculdade de Direito e ex-membros da assessoria, alguns mestrandos e doutorandos, evidenciando-se assim, que a peça chave para a manutenção da solidez dessa estrutura é o trabalho de organização dos alunos, que não são apenas responsáveis pelo bom desempenho dos trabalhos, como também viabilizam a perpetuação e o crescimento da Assessoria.

Iniciadas as atividades para atender a comunidade externa, logo após o seu surgimento a AJHE passou a voltar-se para dentro da Universidade, auxiliando as empresas juniores constituídas em outros cursos jurídicos, favorecendo a atividade interdisciplinar. ${ }^{13}$

No âmbito da Universidade Federal do Rio Grande do Sul, já há onze empresas juniores constituídas, e mais da metade delas foram assessoradas pela AJHE. Além das empresas juniores, a AJHE auxilia também microempresas, empresários individuais e startups, devendo, todos esses, serem dotados de uma característica em comum: a ausência de condições econômicas para contratação de um profissional especializado. Tal característica se impõe pois a Assessoria apenas presta atendimento àqueles que não possuem condições financeiras de arcar com os custos de um advogado, tendo em vista as exigências éticas e deontológicas que disciplinam a atividade do advogado ${ }^{14}$.

Os resultados das atividades realizadas pela AJHE têm sido satisfatórios, seja perante a comunidade acadêmica, como também no meio empresarial, o que é evidenciado pelo

\footnotetext{
${ }^{13} \mathrm{O}$ Brasil conta hoje com o auxílio de 1.200 empresas juniores, o que lhe gratifica com o título de líder mundial destas empresas, passando à frente da Europa, permitindo, assim, a superação das lacunas práticas muitas vezes presentes nas universidades. Os benefícios não se restringem apenas ao solicitante do serviço e aos estudantes que o prestam, mas se estendem à economia brasileira, tendo em vista que, segundo dados da Confederação Brasileira de Empresas Juniores - Brasil Júnior -, em 2016 os lucros alcançados por essas instituições atingiram o patamar de 11,1 milhões de reais. A propósito do tema ver XAVIER, Renan e COSTA, Daiane. Com 1,2 mil empresas
}

crescimento de casos atendidos a cada ano, havendo, atualmente, cerca de dez casos sendo trabalhados pelos membros da Assessoria. Do período de 2011 até o presente momento, cerca de 43 casos foram solucionados pela AJHE, muitos dos quais com grau de complexidade significativo por envolver mais de uma área e com longo tempo de atuação, o que demonstra a efetividade prática da Assessoria, que almeja poder participar e fomentar cada vez mais os empreendimentos acadêmicos e sociais através da prestação de serviços gratuitos e de qualidade.

Com isto, observa-se que a Assessoria Jurídica Hernani Estrella, além de possibilitar um aprendizado mais rico para o aluno que se dedica ao estudo do Direito Empresarial, beneficia não somente alunos do Direito. Outros cursos da UFRGS, que também estimulam a prática das Empresas Juniores, encontram na AJHE uma aliada estratégica e a principal salvaguarda para as necessidades jurídicas de que suas empresas juniores necessitam em um momento em que não há recursos para bancá-las. Com isso, nota-se a consolidação dos estudantes como protagonistas da vida universitária e social, estabelecendo uma rede mútua de suporte e trazendo resultados benéficos para diferentes cursos da UFRGS, beneficiando o ensino da instituição como um todo, afirmando a liderança e a maturidade dos alunos em sua vida acadêmica, produção intelectual e protagonismo universitário.

É importante destacar que a atuação na Assessoria Jurídica Hernani Estrella promove o aprimoramento do estudante não só de seu entendimento da matéria do grupo de trabalho de que participa na AJHE, como também o desenvolvimento de características como liderança, trabalho em equipe, responsabilidade, entre outros valores essenciais para a vida

juniores, Brasil é líder mundial no segmento. O Globo, 07 ag. 2016; PAMPLONA, Patrícia; FREITAS, Olívia. Folha de São Paulo, São Paulo, 06 jun. 2016; e https://www.brasiljunior.org.br/brasil-junior/noticias/quaograndes-seremos-em-2017

${ }^{14}$ BRASIL. Código de Ética e Disciplina da Ordem dos Advogados do Brasil. Aprovado pela Resolução 02/2015. Brasília, DF, 19 out. 2015; BRASIL. Lei n ${ }^{\circ} 8.906$, de 4 de julho de 1994. Dispõe sobre o Estatuto da Advocacia e a Ordem dos Advogados do Brasil (OAB). Diário Oficial, Brasília, DF, 05 jul. 1994. 
profissional. O trabalho junto à AJHE também favorece o desenvolvimento do domínio da terminologia técnica e linguagem própria da área comercial, facilitando o contato e o diálogo entre os futuros profissionais do Direito com os seus clientes, aproximando-os da realidade fática e sensibilizando-os para as questões jurídicas e sociais atinentes à atividade mercantil. Desta forma consolidam as organizações estudantis como principais protagonistas do desenvolvimento do conhecimento universitário muito mais do que teórico, também prático e conectado à realidade diária - e elo de ligação entre a faculdade e a sociedade que a circunda.

\section{CONCLUSÃO}

A conclusão deste breve artigo descritivo da atividade de extensão é de que a atividade redunda em benefícios sociais indiretos, porém profundos, tendo em vista que a Universidade "entregará" para a sociedade profissionais melhor qualificados e integrados à realidade social, com capacidade para realização de serviços de interesse social elevado e aplicação do conhecimento adquirido para além dos muros universitários.

Mais do que deixar profundas marcas em artigos, livros ou bancos de dados, a Assessoria Jurídica Hernani Estrella deixa suas mais destacadas impressões na vida daqueles que nela trabalharam e que dela receberam ajuda, pois desenvolveram a capacidade de atuar coletivamente em torno de um projeto cujo resultado social é evidente, colhendo frutos sob a perspectiva acadêmica como sob a perspectiva de sua futura carreira profissional.

Em uma outra perspectiva, deve-se dizer que a AJHE deixa marcas inclusive sob o ponto de vista da Extensão Universitária, pois conseguiu desenvolver um modo de atuação peculiar em relação às políticas de extensão, que na área jurídica são limitadas aos problemas vinculados aos Direitos Humanos e Fundamentais, conforme as próprias linhas que historicamente marcaram as atividades de extensão. ${ }^{15}$

Trata-se de uma marca na linha histórica das atividades de extensão relativamente ao papel da Universidade na relação com a sociedade, pois ainda que as atividades possam ter um caráter assistencial em razão a ausência de cobrança pelos serviços, o papel central da atividade está voltado para a integração das atividades de pesquisa e ensino com a realidade econômica e social. ${ }^{16}$

\section{REFERÊNCIAS}

ANTUNES, José Engrácia. Estrutura e responsabilidade da empresa: o moderno paradoxo regulatório. In: CUNHA, Alexandre dos Santos (Org.). O Direito da Empresa e das Obrigações e o novo Código Civil brasileiro. SP: Quartier Latin, 2006, p. 17 - 65.

ASCARELLI, Tullio. Panorama do Direito Comercial. Sorocaba: Minelli, 2007.

ASQUINI, Alberto. Perfis da empresa. Tradução de Fábio Konder Comparato. Revista de Direito

15 "O Forproex organizou a atuação da extensão universitária em oito áreas temáticas: saúde, educação, trabalho, meio ambiente, comunicação, direitos humanos e justiça, tecnologia de produção e cultura. Essas áreas podem ser agrupadas de vários modos. Um agrupamento possível é o que estabelece dois grupos, a saber: um grupo regido pelos temas atinentes aos chamados direitos de primeira e segunda geração, isto é, aqueles que a partir da Revolução Francesa estabeleceram direitos individuais, típicos do ideário liberal clássico burguês, a saber: o direito à saúde, educação, trabalho e cultura. Um segundo grupo de temas é o representativo dos direitos emergentes contemporâneos como é o caso dos direitos humanos pensados a partir de uma cidadania ampliada: o direito ao meio ambiente saudável e sustentável; o direito à informação e à comunicação livres e qualificadas; o direito de apropriação e geração de novas tecnologias". PAULA, João Antônio de. A extensão universitária: história, conceito e propostas. Belo Horizonte. Interfaces - Revista da Extensão da UFMG, v. 1, 2013, p. 17.

${ }^{16}$ Neste mesmo sentido são as atividades de outro programa de extensão desenvolvido na UFRGS, que é o NEF, Núcleo de Estudos em Direito Empresarial e Falências, descrito no artigo BRANCO, Gerson. L. C. ; PIVA, Luciano. Z ; CRUZ, Diogo. M.; FREITAS, Nakita. Prática em falência e recuperação da empresa: um espaço para estudo e construção do conhecimento da liberdade negocial. Porto Alegre: UFRGS, Revista da Extensão, v. 6, p. 64-72, 2013. 
Mercantil, Industrial, Econômico e Financeiro. São Paulo, v. 35, n. 104, out./dez. de 1996.

BRANCO, Gerson. L. C.; PIVA, Luciano. Z.; CRUZ, Diogo. M.; FREITAS, Nakita. Prática em falência e recuperação da empresa: um espaço para estudo e construção do conhecimento da liberdade negocial. Porto Alegre: UFRGS, Revista da Extensão, v. 6, p. 64-72, 2013.

CAVALli, Cássio. Empresa, Direito e Economia. Rio de Janeiro: Forense, 2013.

COASE, R. H. The nature of the Firm. Economica, New Series, v. 4, n. 16, 1937, p. 386 - 405.

COSTA, Daiane; XAVIER, Renan. Com 1,2 mil empresas juniores, Brasil é líder mundial no segmento. O Globo, 07 ag. 2016.

FORGIONI, Paula Andréa. A evolução no Direito Comercial Brasileiro: da mercancia ao mercado. São Paulo: Revista dos Tribunais, 2009.

FRAZÃO, Ana. Função Social da Empresa. São Paulo: Renovar, 2011.

JEZINE, Edineide. As Práticas Curriculares e a Extensão Universitária. Belo Horizonte. Anais do $2^{\circ}$ Congresso Brasileiro de Extensão Universitária Belo Horizonte - 12 a 15 de setembro de 2004.

LAMY FILHO, Alfredo; PEREIRA, José Luiz Bulhões. Direito das Companhias. Vol I. Rio de Janeiro: Forense, 2009.

MARCONDES, Sylvio. Problemas de Direito Mercantil.São Paulo: Saraiva, 1970.

MARTINS-COSTA, Judith e BRANCO, Gerson Luiz Carlos. Diretrizes Teóricas do novo Código Civil. São Paulo: Saraiva, 2002.

MOREIRA ALVES, José Carlos. Inovações no novo Anteprojeto de Código Civil. Revista de Informação Legislativa, out/dez de 1973, p.5 - 15.

PAMPLONA, Patrícia; FREITAS, Olívia. Folha de São Paulo, São Paulo, 06 jun. 2016.

PAULA, João Antônio de. A extensão universitária: história, conceito e propostas. Belo Horizonte. Interfaces - Revista da Extensão da UFMG, v. 1, 2013.

REALE, Miguel. O Anteprojeto do Código Civil. São Paulo: Saraiva, 1972.

REALE, Miguel. Visão geral do Projeto de Código Civil. Revista dos Tribunais, v. 752, jun. 1998.

WIEDMANN, Herbert. Direito Societário I - Fundamentos. In: NOVAES E FRANÇA, Erasmo Valadão: Temas de Direito Societário, Falimentar e Teoria da Empresa. São Paulo: Malheiros, 2009.

Recebido em: 11/05/2017

Aceito em: 29/10/2017 
Assessoria Jurídica Hernani Estrella: ambiente de desenvolvimento do empreendedorismo e fomento do aprendizado do Direito Empresarial

Revista da Faculdade de Direito da UFRGS, Porto Alegre, n. 36, p. 30-39, vol. esp., out. 2017.

ISSN: 0104-6594 Site http://seer:ufrgs.br/revfacdir

Faculdade de Direito da UFRGS - Rua Riachuelo, 1317 - Centro - Porto Alegre - RS - Brasil 